\title{
Individual development plans - experiences made in graduate student training
}

\author{
Amar H. Flood ${ }^{1}$ - Sara E. Skrabalak ${ }^{1} \cdot{\text { Yan } \mathrm{Yu}^{1}}^{1}$ \\ Accepted: 8 July 2021 / Published online: 14 August 2021 \\ (C) Springer-Verlag GmbH Germany, part of Springer Nature 2021
}

\section{Introduction}

Graduate education is one of the cornerstones of academic research. Students dedicate many years to a research group and project, developing and applying skills so that they can contribute new knowledge to a field and, in return, become independent scientists. Beyond the application of their technical expertise, individuals who attain advanced degrees are also often expected to take on additional roles in their careers. These roles can involve project and people management, communication of outcomes, fundraising and budgetary oversight, and much more. Yet, often, the manner in which skills are developed for such roles is haphazard at best and may occur without alignment with individual career goals or institutional priorities. These realizations have prompted many graduate programs to implement workshops and entire courses toward professional development. There are even trainings available for faculty and program directors interested in implementing professional development activities, for example the Entering Research curriculum available through the Center for the Improvement of Mentored Experiences in Research at the University of Wisconsin [1].

Common themes in professional development initiatives for graduate students include development of interpersonal communication skills, disciplinary knowledge, science communication skills, critical thinking skills, understanding of the research environment and enterprise, project design skills, ethical research skills, research identity, and ultimately confidence and independence as a scientist [1]. The multi-faceted nature of graduate studies can overwhelm students, and at worse can lead to anxiety, depression, and general dissatisfaction $[2,3]$. Thus, professional development initiatives in

Sara E. Skrabalak

sskrabal@indiana.edu

1 Department of Chemistry, Indiana University - Bloomington, 800 E. Kirkwood Ave, Bloomington, IN 47405, USA graduate programs must also equip students to clarify their goals so that they can identify and then efficiently engage in the most meaningful activities toward career advancement. Individual development plans (IDPs) are a tool that can help students in such goal setting and achievement.

\section{Individual development plans}

IDPs have a long history of use in industry and government and are becoming more common in academia $[4,5]$. They are generally viewed as tools to assist employees in achieving career goals by emphasizing self-development in alignment with an institution's goals. They are often used to facilitate discussion and may take different forms depending on the work or training environment. For example, a list of SMART (Specific, Measurable, Attainable, Relevant, and Time-Bound) goals mapped onto a calendar may suffice in some situations [6]. myIDP from the American Association for the Advancement of Science (AAAS; http://myidp. sciencecareers.org/) [7] and ChemIDP from the American Chemical Society (https://chemidp.acs.org/) [8] are Webbased IDP platforms well-suited for students in the chemical sciences. Both provide structured exercises that guide students to examine their skills, interests, and values in alignment with scientific career paths. These exercises are coupled with goal setting initiatives and accountability measures to help students strengthen critical professional and technical skills.

\section{Introducing IDPs in graduate professional development courses}

In the Department of Chemistry at Indiana University, IDPs are introduced and used in a variety of graduate student training settings. Herein, these efforts and lessons learned are discussed so that those unfamiliar with IDPs can evaluate if implementation would add value in their training initiatives. 
IDP philosophy was introduced into the education of our graduate students in 2013 when AHF first became the Director of Graduate Studies (DGS) for the Department of Chemistry and continued when SES took over as the current DGS. The IDP materials were incorporated into a new course focused on Graduate Professional Development, which also emphasized pedagogy with direction by colleagues C. Reck and M. Porter. Together, we created a 1-credit (14, 1-h sessions) course that was required of and provided all first-semester chemistry graduate students ( $\sim 40-50$ students) with a curriculum to cultivate a suite of skills valuable at the beginning of their research career as well as for their growth during the program as they headed toward graduation. A diversity of topics is included, with some variation from year-to-year and with instructor. Table 1 lists the topics from the fall 2020 syllabus.

A key objective of this course was to provide students with skills for advancing their professional development. Around this time, the NIH was advocating use of IDPs with the graduate students and postdoctoral scholars that were supported by research grants $[9,10]$. The spirit of the IDPs resonated with the goals of the new course we were developing. Actual IDPs were not implemented in the course directly at that early stage because we were all quite new to the process. Instead, the elements of IDPs were introduced during the course. These included identifying professional goals that are outside of research objectives and providing students with a broader context for how those types of activities contribute to them becoming professionals during the course of their studies. These goals should follow the interests of the students. Examples could include outreach activities that may also be offered outside of the student's research group, participation in leadership roles associated with graduate student-led societies and committees (e.g., Chemistry Graduate Representatives Committee and the student chapter of the Materials Research Society on campus), science writing opportunities on campus, and science policy internships offered by AAAS.

The implementation of the IDP philosophy and the Graduate Professional Development course were well received by students and faculty alike, as indicated by departmental graduate student climate surveys. The course has evolved and, with the times, has given rise to many positive changes in graduate student life and culture. Starting in 2019, first-year graduate students were expected to set up their $m y I D P$ profile from AAAS as part of the course. This interface was selected over other excellent resources as several multi-department training programs on campus have begun introducing IDP philosophy, and we wanted to have a standard platform across scientific disciplines. The myIDP interface also links to a dozen articles that can guide students and instructors alike with the implement of IDPs [7].

Students also share examples of both short- and long-term SMART goals from their myIDP profile in small group breakouts. As the DGS overseeing this exercise, SES has noted that the sharing of SMART goals facilitates class cohesion and accountability pairings as many students have similar ambitions and insecurities. Students are encouraged to keep their $m y I D P$ profiles up-to-date as a means of tracking individual growth, with SES using students' IDPs in her office hours as DGS when discussing program progress and challenges within graduate study. From the DGS perspective, the IDP model empowers students to take ownership of their graduate training while also illustrating the value of a broad support network during graduate study, not just one centered on the student-thesis chair relationship.

The philosophy, use, and review of IDPs have been discussed in faculty meetings so that individual faculty may make use of these tools in their advising of research students.

Table 1 Topics discussed during the fall 2020 Professional Development Course for first-semester chemistry graduate students at Indiana University. Listed in order of presentation

1. Graduate Career Planning: Developing Your Own 4-5 Year Plan and an Introduction to Individual Development Plans

2. Identifying Your Research Interests and Identifying Your Advisor Needs

3. CV and IDP Review

4. What to Look for in Potential Research Groups; Panel with Senior Graduate Students

5. Learning Theories and Active Learning for Discussion Sections

6. Best Practices for Laboratory Classes

7. Library Resources, Reference Management, and Getting to Know the Literature

8. Growth Mindset and Graduate Studies

9. Check-in and Open Discussion with the Director of Graduate Studies

10. Scientific Ethics: Conflicts of Interest, Authorship, Data Management, Human Subjects, Mentor/Mentee Responsibilities/Relationships

11. How to Be a Successful Graduate Student: Becoming an Independent Learner, Interacting with your PI and Committee, and Goal Setting

12. Starting and Success in Graduate Studies: How to Collect and Record Data, What makes Good/Bad Data, Time Management, and More - a Panel of Faculty

13. Navigating a Diverse Research Environment (Diversity, Equity, and Inclusion in the Work Environment)

14. Writing Your Initial Research Plan 
Presented next is a personal reflection by YY of IDP use in graduate student advising.

\section{Use of IDPs in research advising: a personal reflection}

When I (YY) started in my tenure track position at Indiana University in 2012, I sometimes found myself at a loss with mentoring graduate students. I was eager to help them achieve their potential, but I struggled with finding an effective way to bring out the individual strengths in each of them. There were also times when I wished I knew my students better and wished for some channel for open and effective communication with them. So I turned to books to search for an answer [11, 12]. Most of the books were written for new managers in industrial settings, but nevertheless they opened my eyes to many interesting ideas. I was particularly intrigued by the idea of doing one-on-one "career improvement plans" with mentees, which is very much like a simplified version of an IDP. I wasn't aware of term IDP at the time but was so intrigued by the idea that I decided to give it a try.

I still vividly remember how the first one-on-one IDP meetings went with my students. Prior to the meetings, I had asked them to write down a list of reflections, including long-term career goals, short-term monthly milestones, strengths, areas to improve, and an action plan for improvement. I also wrote down my perceptions prior to the meetings. At the individual meetings, I was pleasantly surprised by the frankness of the students. All of them clearly outlined their short-term and long-term goals with very thoughtful strategic plans. As a matter of fact, most students were quite harsh in assessing their areas of improvement but reluctant to identify their areas of strength. It was quite striking to me to see the students through their own eyes. When it was time for me to provide feedback, I made an effort to emphasize their strengths. I still remember the looks on the students' faces when they heard me highlighting each of their strengths - there was a mixture of surprise, appreciation, and pride. One student told me afterwards that everyone in the lab enjoyed the IDP meetings because they felt guided, heard, and appreciated. Needless to say, I enjoyed the meetings too.

Over the years, our first version of career development plans has morphed gradually into a more detailed format. We have also re-structured our regular IDP meetings. Currently, I have one-on-one IDP meetings with my lab members once every month to mostly focus on short-term goals and self-assessment of the past month. The end-of-year IDP meetings are then focused more on the long-term goals, assessment of their yearly achievements, and action plan for the new year. The short-term IDP we now use at our monthly meetings is a shortened version of what is available in myIDP. It includes categories like "effective experimental design", "critical analysis of data", "time management", "literature reading", "writing and presentation skills", "milestones for next month", etc. A question "what extra help do you need from your advisor?" is also included to encourage students to talk about their needs even if the needs are not strictly research related. For example, some of my students have used this question as an opportunity to ask for advice on career choices and my personal experience of work-life balance. At the IDP meetings, I find it is important to create an atmosphere where students can feel comfortable to talk openly without being judged and to drive the meeting, while I mostly listen. Because most students have done an amazing job identifying their areas to improve, I mostly focus my comments on applauding their strengths and improvements they have made since the last IDP meeting, and giving suggestions to their action plan when needed.

I have found that doing the regular IDP practice has made a very positive impact on everyone, including myself, as well as the group as a whole. One of the most obvious effects was that the IDPs motivate graduate students and postdoctoral researchers to be proactive in shaping their own research and professional development trajectories. During the process, they learn how to plan strategically toward their short- and long-term goals. They learn how to communicate their needs and ask for assistance when needed. They also learn to pause and reflect regularly amidst daily research activities, so they do not lose sight of the long-term goals. For myself as advisor, doing the IDPs with my mentees has been equally beneficial. It provides a formal yet friendly setting to communicate expectations. More importantly, the IDP practice provides for an open and direct dialogue between my mentees and myself. Based on my experience, students are much more likely to talk about issues that they would otherwise feel reluctant to talk about in other settings. Hearing them talk about their career goals, their self-assessment of strengths and weaknesses, and sometimes their struggles has allowed me to take a more personalized approach to their training. Every graduate student has different goals and ambitions; I believe the responsibility of a research advisor is to help them achieve their potential regardless of the career path they choose. The IDP is one of the most useful tools I have found to help me effectively carry out that responsibility. Similar to our experience, the positive impact of IDPs on the lab productivity and the creation of healthy lab culture has also been detailed by members of the DePace group at Harvard University [13]. To promote the use of IDPs by other faculty in our department, I have at faculty meetings given brief tutorials on IDPs and shared my experience of incorporating IDPs in student mentoring. 


\section{Final comments}

Whether using Web-based IDP tools or personalized templates for career development, we have found the IDP model to add value to graduate training. Some management experts are critical of IDPs for putting too much emphasis on individual weaknesses, suggesting that every individual can master a full-suite of skills, or the rigidity of advising templates [4]. In our experience, IDPs are a highly flexible platform where students' strengths and interests can be leveraged and different formats can be implemented depending on the individuals involved. Moreover, we have found that introducing the underlying philosophy of IDPs to be a benefit to our graduate training initiative with its emphasis on student individuality and independence, which are hallmarks of graduate education.

\section{Declarations}

Conflict of interest The authors declare no competing interests.

\section{References}

1. Branchaw JL, Butz AR, Smith A. Entering research: a curriculum to support undergraduate \& graduate research trainees. 2nd ed. New York, NY: Macmillan Publishers Ltd; 2020.

2. Puri P. The emotional toll of graduate school. In: Scientific American Blog. 2019. https://blogs.scientificamerican.com/observations/theemotional-toll-of-graduate-school/. Accessed 29 May 2021.

3. Woolston C. Graduate survey: a love-hurt relationship. Nature. 2017;550(7677):549-52. https://doi.org/10.1038/nj7677-549a.

4. JJacobson D. Using IDPs to leverage strengths. In: Growing Leaders for the Public Service Website. 2002-2021. www. govleaders.org/idp.htm. Accessed 29 May 2021.

5. Hobin JA, Clifford PS, Dunn BM, Rich S, Justement LB. Putting PhDs to work: career planning for today's scientist. CBE Life Sci Educ. 2014;13(1):49-53. https://doi.org/10.1187/cbe-1304-0085.

6. Bovend'Eerdt TJH, Botell RE, Wade DT. Writing SMART rehabilitation goals and achieving goal attainment scaling: a practical guide. Clin Rehabil. 2009;23(4):352-61. https://doi.org/10.1177/ 0269215508101741

7. myIDP. In: Science Magazine Website. 2013. http://www. sciencemagorg/careers/2013/05/myidp. Accessed 29 May 2021.

8. ChemIDP: American Chemical Society's Career Planning Tool. In American Chemical Society Website. 2021. https://www.chemidp. acs.org. Accessed 292021.

9. Revised Policy: Descriptions on the Use of Individualized Development Plans (IDPs) for Graduate Students and Postdoctoral Researchers Required in Annual Progress Reports beginning October 1, 2014. In: National Institutes of Health Website. 2014. https://grants.nih.gov/grants/guide/notice-files/not-od-14113.html. Accessed 29 May 2021.

10. Biomedical Research Workforce Working Group Report. In National Institutes of Health Website. 2012. https://acd.od.nih.gov/documents/ reports/Biomedical_research_wgreport.pdf. Accessed 29 May 2021.

11. Belker LB, McCormick J, Topchik GS. The first-time manager. 6th ed. New York, NY: American Management Association; 2012.

12. Bolton R, Bolton DG. People styles at work and beyond: making bad relationships good and good relationships better. 2nd ed. New York, NY: American Management Association; 2009.
13. Vincent BJ, Scholes C, Staller MV, Wunderlich Z, Estrada J, Park $\mathrm{J}$, et al. Yearly planning meetings: individualized development plans aren't just more paperwork. Mol Cell. 2015;58(5):718-21. https://doi.org/10.1016/j.molcel.2015.04.025.

Publisher's note Springer Nature remains neutral with regard to jurisdictional claims in published maps and institutional affiliations.

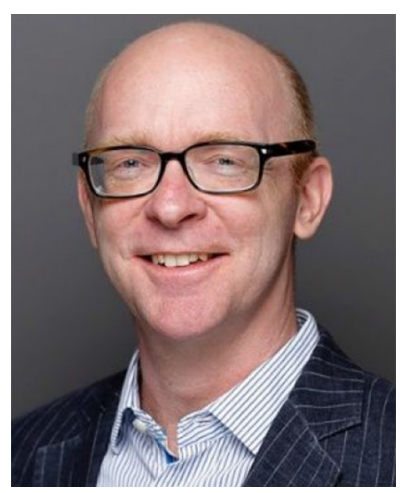

Amar H. Flood is a Professor of Chemistry at Indiana University where he conducts research on supramolecular chemistry, molecular switches, and fluorescent materials derived from anion coordination chemistry. Course teaching at the graduate level complements these interests. He enjoys mentoring graduate student coworkers in the art of research and fostering student-directed experiences both inside and outside the lab.

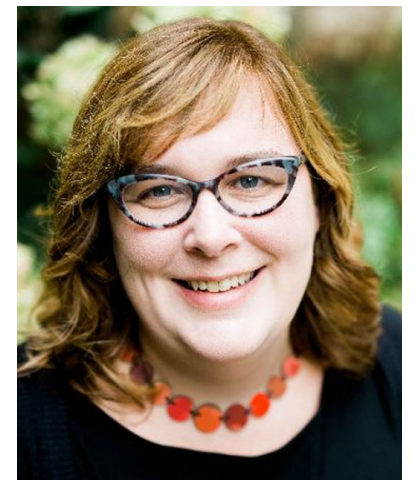

Sara Skrabalak is James H. Rudy Professor at Indiana University in the Chemistry Department where she conducts research on nanomaterial synthesis for plasmonics and catalysis as well as energy and security applications. In 2019, she was appointed Director of Graduate Studies for the Chemistry Department where she seeks to empower graduate students to pursue the program of their dreams through the "mentoring up" philosophy. She is Editor-in-Chief for Chemistry

of Materials and ACS Materials Letters

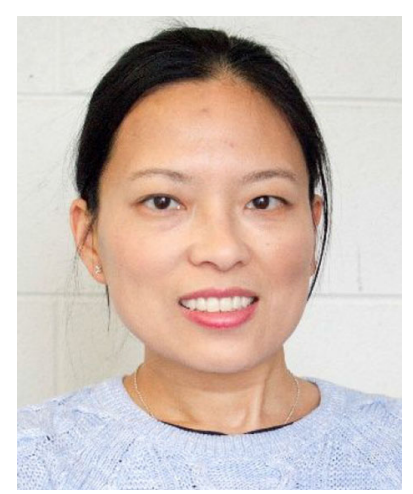

Yan Yu is Associate Professor in the Department of Chemistry at Indiana University Bloomington. Her research interests focus on understanding molecular assembly, dynamics, and interactions at cell-material interfaces. She received her B.S. degree in Chemistry from Peking University (China) in 2004 and $\mathrm{Ph} . \mathrm{D}$. degree in Materials Science and Engineering from the University of Illinois at Urbana-Champaign in 2009. After her postdoctoral training at the University of California - Berkeley, she joined Indiana University as Assistant Professor in 2012. 